Fidei: Jurnal Teologi Sistematika dan Praktika, Vol. 4, No. 2, Des. 2021

Fidei: Jurnal Teologi Sistematika dan Praktika

\title{
Spiritualitas dalam Peribadahan Kristen bagi Keharmonisan Umat: Refleksi Efesus 5:18-21
}

\section{Joseph Christ Santo, Joko Sembodo, Asih Rachmani Endang Sumiwi, ${ }^{1}$ Mariani Harmadi ${ }^{2)^{*}}$ \\ 1) Sekolah Tinggi Teologi Torsina, Indonesia \\ 2) Sekolah Tinggi Teologi Baptis Indonesia, Indonesia \\ *) E-mail: jx.santo@gmail.com}

Diterima: 05 Sep. 2021 Direvisi: 23 Nov. 2021

Disetujui: 28 Nov. 2021

\begin{abstract}
Abstrak
Spiritualitas memiliki definisi yang beragam, dalam lingkup kekristenan spiritualitas dikaitkan dengan roh yang merupakan unsur terdalam dari manusia, yang mana roh manusia ini memiliki relasi dengan Allah yang adalah roh. Pada umumnya spiritualitas merujuk kepada hubungan individu tersebut dengan Tuhan; penelitian ini memaparkan sisi lain yang belum banyak dibahas, yaitu sisi sosial dari spiritualitas. Efesus 5:18-21 membahas spiritualitas dalam ibadah, tetapi beberapa kata yang digunakan dalam nas ini mengandung unsur relasional sehingga muncul pertanyaan bagaimana keterkaitan spiritualitas dalam ibadah dengan hubungan antarwarga jemaat. Hasil penelitian eksegesis menunjukkan bahwa spiritualitas orang Kristen adalah kondisi seorang Kristen yang mampu menguasai diri karena rohnya ada dalam kendali Roh Kudus; spiritualitas dalam peribadahan yang didasari penuh dengan Roh akan membentuk relasi yang baik antarwarga jemaat, dan pada akhirnya menghasilkan keharmonisan umat Allah.
\end{abstract}

Kata-Kata Kunci: Efesus 5; Ibadah; Keharmonisan; Penuh Roh; Spiritualitas

\section{Abstract}

Spirituality has various definitions, within the scope of Christianity spirituality is associated with the spirit which is the deepest element of man, 
where the human spirit has a relationship with God who is spirit. In general, spirituality refers to the individual's relationship with God; This study describes another side that has not been widely discussed, namely the social side of spirituality. Ephesians 5:18-21 discusses spirituality in worship, but some of the words used in this passage contain relational elements, so the question arises of how spirituality in worship relates to the relationship between members of the congregation. The results of exegesis research showed that Christian spirituality is the condition of a Christian who can control himself because his spirit is under the control of the Holy Spirit; spirituality in worship that is based on the fullness of the Spirit will build a good relationship between the members of the congregation, and in the end, result in the harmony of God's people.

Keywords: Ephesians 5; Full Of Spirit; Harmony; Spirituality; Worship.

\section{Pendahuluan}

Ibadah merupakan bentuk bakti dan pengabdian manusia kepada Tuhan. Ibadah dapat dikaitkan dengan spiritualitas. Hal ini dapat dipahami karena spiritualitas diartikan sebagai sumber motivasi dan emosi pencarian individu yang berkenaan dengan hubungan seseorang dengan Tuhan. ${ }^{1}$ Kata spiritualitas berasal dari kata spirit yang berarti roh atau sukma, dan juga berarti semangat. ${ }^{2}$ Tetapi apakah orang yang beribadah serta-merta menunjukkan bahwa ia memiliki spiritualitas yang baik? Memang kata spiritualitas merupakan kata yang lentur, dalam arti pengertiannya tergantung pada persepsi penggunanya. ${ }^{3}$ Astuti mengaitkan spiritualitas dengan hidup dalam kebenaran dan kekudusan. ${ }^{4}$ Barus mendefinisikan spiritualitas sebagai gaya dan sikap hidup dari Kristus, bersama Kristus, untuk Kristus dan demi Kristus. ${ }^{5}$ Dalam alam berpikir Kristen, spiritualitas lebih dipahami dalam konteks pengembangan roh karena asosiasi kata spiritualitas dengan aspek kerohanian manusia. ${ }^{6}$

Dalam surat kepada jemaat Galatia, Paulus membandingkan orang yang hidup dalam hidup dalam roh dan yang hidup dalam keinginan daging (Gal. 5:16-17). Orang yang hidup dalam keinginan daging melakukan perbuatanperbuatan yang tercela (Gal. 5:19-21). Dengan kata lain, spiritualitas juga dapat

${ }^{1}$ Kamus Besar Bahasa Indonesia, 5th ed. (Badan Pengembangan Bahasa dan Perbukuan, Kementerian Pendidikan dan Kebudayaan Republik Indonesia, 2021), spiritualitas.

${ }^{2}$ Kamus Besar Bahasa Indonesia.

${ }^{3}$ Armand Barus, "Spiritualitas Surat Kolose," Jurnal Amanat Agung 12, no. 1 (2016): $39-62$.

${ }^{4}$ Tri Astuti, "Studi Biblika Spiritualitas Manusia Baru Berdasarkan Surat Efesus 4: 23 32," SHIFT KEY: Jurnal Teologi dan Pengembangan Pelayanan 10, no. 1 (2020): 26-44.

${ }^{5}$ Barus, "Spiritualitas Surat Kolose."

${ }^{6}$ Adolf Heuken, Spiritualitas Kristiani: Pemekaran Hidup Rohani Selama Dua Puluh Abad (Jakarta: Yayasan Cipta Loka Caraka, 2002). 
diartikan sebagai kesanggupan seseorang mengekang hawa nafsu. Arifianto membandingkan manusia rohani dengan manusia duniawi; diindikasikan bahwa manusia rohani terus bertumbuh, memiliki kesadaran untuk berubah, dan memberikan buah yang baik. ${ }^{7}$

Dalam lingkup teologi Pentakosta dikenal istilah penuh Roh atau penuh dengan Roh. Beberapa ahli mengaitkan istilah ini dengan peristiwa baptisan Roh Kudus yang dialami seseorang, yang berlanjut pada penguasaan Roh Kudus atas kehidupan orang tersebut baik dalam konteks ibadah maupun dalam hidup sehari-hari. Sesuai dengan kelenturan definisi spiritualitas, maka spiritualitas juga dapat dikaitkan dengan penuh Roh yang dimaknai dengan seberapa kuat hidup seseorang ada dalam kendali Roh Kudus.

Dari sudut pandang teologi Pentakosta, Siahaan mereinterpretasi spiritualitas dalam narasi peristiwa Pentakosta yang diikuti fenomena bahasa roh sebagai spiritualitas perikoresis. ${ }^{8} \mathrm{Di}$ sisi lain Baskoro dan Siburian mengemukakan bahwa spiritualitas pelayanan Pentakosta-Karismatik dikaitkan dengan berbagai pengalaman spiritual. ${ }^{9}$ Peneliti melihat spiritualitas berhubungan dengan penuh Roh, yang perlu dipahami keterkaitannya dengan koinonia, sebuah ruang sosial dalam kehidupan bersama orang Kristen. Wujud koinonia adalah dengan menghayati hidup berjemaat, yaitu bersama-sama berkumpul menghadap hadirat Tuhan, bernyanyi dan berdoa bersama, melakukan pelayanan sakramen, meneguhkan dan menguatkan orang yang lemah, serta saling melayani dalam kepedulian bersama. ${ }^{10}$

Ketika Paulus menuliskan pesannya dalam surat Efesus, dengan modus imperatif ia mengatakan $\pi \lambda \eta \rho 0 \tilde{\theta} \theta \varepsilon \dot{\varepsilon} v \pi v \varepsilon v ́ \mu \alpha \tau \iota$ (plèrousthe en pneumati) yang berarti, "hendaklah kalian penuh di dalam roh." Menarik sekali bahwa perintah atau permohonan ini tidak berdiri sendiri melainkan diikuti dengan beberapa tindakan resiprok (saling). Artinya konsep penuh Roh tidak berhenti pada pengalaman individu melainkan ada langkah selanjutnya di ruang sosial.

Beberapa penelitian tentang spiritualitas berdasarkan surat Efesus telah dilakukan, beberapa di antaranya adalah sebagai berikut: Nazara telah meneliti

${ }^{7}$ Yonatan Alex Arifianto, "Kajian Biblikal Tentang Manusia Rohani Dan Manusia Duniawi," Jurnal Teruna Bhakti 3, no. 1 (2020): 12-24.

${ }^{8}$ Harls Evan R. Siahaan, "Bahasa Roh Dan Spiritualitas Perikoresis Dalam Peristiwa Pentakosta: Analisis Reinterpretatif Kisah Para Rasul 2:1-13," Logia: Jurnal Teologi Pentakosta 2, no. 2 (2021): 18-31.

${ }^{9}$ Haryadi Baskoro and Hendro H. Siburian, "Keseimbangan Antara Spiritualitas Dan Intelektualitas Dalam Pelayanan Pastoral-Karismatik," FIDEI: Jurnal Teologi Sistematika dan Praktika 2, no. 1 (2019): 123-144.

${ }^{10}$ Stimson Hutagalung, "Tugas Panggilan Gereja Koinonia: Kepedulian Allah Dan Tanggung Jawab Gereja Terhadap Kemiskinan,” Jurnal Koinonia 8, no. 2 (2016): 93-102. 
seluruh kitab Efesus, khususnya tentang doa dalam pembentukan spiritualitas. ${ }^{11}$ Waharman melakukan penelitian eksegesis terhadap Efesus 6:1-4 tentang peran orang tua dalam pertumbuhan spiritualitas anak. ${ }^{12}$ Dengan menggunakan nas yang sama Sitepu, Karo-karo, dan Situmorang meneliti spiritualitas dalam Efesus 6:1-4 dan mengaitkannya budi pekerti siswa; hasilnya adalah ada hubungan yang signifikan antara keduanya. ${ }^{13}$ Nas lain dalam surat Efesus yang juga menjadi dasar penelitian tentang spiritualitas adalah Efesus 4:23-32. Astuti menyelidiki spiritualitas manusia baru berdasarkan Efesus 4:23-32, ${ }^{14}$ sedangkan Siagian lebih fokus pada ayat 23 untuk meneliti pertumbuhan rohani sebagai dasar pertumbuhan jemaat. ${ }^{15}$ Bagian lain surat Efesus, yaitu 4:11-16, telah diteliti oleh Baskoro dan Anggiriati yang meneliti implementasi pemuridan bagi pertumbuhan rohani jemaat. ${ }^{16}$ Sementara Mutak melakukan penelitian atas Efesus 4:13 tentang formasi spiritualitas menuju kedewasaan spiritual. ${ }^{17}$

Dari antara hasil-hasil penelitian tersebut, belum ditemukan literatur yang mengangkat spiritualitas berdasarkan Efesus 5:18-20 dan mengaitkannya dengan keharmonisan jemaat. Karena itu peneliti merasa perlu untuk melakukan penelitian yang mengonstruksi konsep spiritualitas berdasarkan Efesus 5:18-20, aktualisasinya dalam peribadahan Kristen, dan dampaknya bagi keharmonisan umat.

\section{Metode Penelitian}

Penelitian ini merupakan penelitian kualitatif yang dilakukan dengan pendekatan eksegesis atas nas Alkitab Efesus 5:18-20, khususnya frasa $\pi \lambda \eta \rho 0 \tilde{\theta} \theta \varepsilon \dot{\varepsilon} v \pi v \varepsilon v \dot{\mu} \mu \alpha \tau$ (plērousthe en pneumati) dan kata-kata penting yang terkait. Analisis dilakukan atas makna leksikal, struktur gramatikal, dan

${ }^{11}$ Aroma Nazara, "Makna Doa Dalam Pembentukan Spiritualitas (Tinjauan Teologis Terhadap Ajaran Paulus Mengenai Doa Dalam Surat Efesus)" (Sekolah Tinggi Teologi Amanat Agung, 2011).

12 Waharman Waharman, "Peran Orang Tua Dalam Pertumbuhan Spiritualitas Anak: Sebuah Studi Eksegetis Efesus 6:1-4," Manna Rafflesia 4, no. 2 (October 2018): 116-129.

${ }^{13}$ Elisabeth Sitepu, Selamat Karo-Karo, and Ucok Rotama Situmorang, "Hubungan Nilai Spiritualitas Menurut Efesus 6:1-4 Dengan Budi Pekerti Siswa Kelas VI SDN 065015 Kemenangan Tani Medan Tuntungan Tahun Ajaran 2020/2021," Jurnal Pendidikan Religius 3, no. 1 (2021).

${ }^{14}$ Astuti, "Studi Biblika Spiritualitas Manusia Baru Berdasarkan Surat Efesus 4: 23-32."

15 Rutam Siagian, "Pembaharuan Rohani Menurut Efesus 4:23 Sebagai Dasar Pertumbuhan Jemaat," Jurnal Scripta Teologi dan Pelayanan Kontekstual 4, no. 2 (2017): 98112.

${ }^{16}$ Paulus Kunto Baskoro and Indra Anggiriati, "Implementasi Pemuridan Dalam Efesus 4:11-16 Bagi Pertumbuhan Rohani Jemaat Di Masa Kini," Sabda: Jurnal Teologi Kristen 2, no. 1 (2021): 242-265.

${ }^{17}$ Alfius Areng Mutak, "Formasi Spiritualitas Sarana Menuju Kedewasaan Spiritual," SOLA GRATIA: Jurnal Teologi Biblika dan Praktika 6, no. 1 (February 2020). 
konteks. ${ }^{18}$ Dengan analisis leksikal diperoleh makna dari frasa tersebut, sehingga dapat dibangun konsep spiritualitas. Dengan analisis gramatikal diperoleh hubungannya dengan frasa-frasa di sekitarnya, sehingga ditemukan dimensi-dimensi dari spiritualitas tersebut khususnya dalam lingkup koinonia (persekutuan warga jemaat). Dengan analisis konteks temuan tersebut dikaitkan dengan situasi pada saat surat Efesus ini ditulis. Selanjutnya dari premis-premis minor spiritualitas tersebut dibangun secara induktif spiritualitas dalam peribadahan jemaat.

\section{Pembahasan dan Hasil}

\section{Refleksi Efesus 5:18-20}

Secara tradisional gereja mengakui bahwa surat ini ditujukan Rasul Paulus kepada jemaat di Efesus. Tidak adanya salam pribadi atau jawaban atas masalah khusus seperti surat kepada Korintus, mengindikasikan bahwa surat ini dimaksudkan untuk diedarkan secara luas, bukan hanya untuk jemaat di Efesus saja. Rasul Paulus menulis surat ini dalam perjalanan sebagai tawanan menuju Roma, diduga kuat surat ini ini ditulis di Roma (Ef. 3:1; 4:1; 6:20). Abineno menyatakan, bahwa surat ini merupakan seruan kepada umat Tuhan supaya mereka menghayati makna rencana agung dari Tuhan itu untuk memersatukan seluruh umat manusia melalui Yesus Kristus. ${ }^{19}$ Pernyataan ini diperkuat oleh Santo yang mengulas kesatuan gereja berdasarkan Efesus 4:1-16. ${ }^{20}$

Jemaat Efesus berdiri diawali dua belas orang yang sebelumnya sudah menerima baptisan Yohanes tetapi belum mengenal pekerjaan Roh Kudus. Kemudian kedua belas orang ini dibaptis oleh Paulus dalam nama Tuhan Yesus. Pada saat Paulus menumpangkan tangan atas mereka, Roh Kudus turun atas mereka, lalu mereka berkata-kata dalam bahasa roh dan bernubuat (Kis. 19:1-7). Bagi jemaat Efesus, pengalaman penuh dengan Roh menjadi momen bersejarah berdirinya jemaat tersebut. Tentunya jika di kemudian hari Paulus berbicara kepada mereka tentang penuh dengan Roh, mereka diingatkan kepada awal pengikutan mereka kepada Kristus.

Berdasarkan isi surat, dapat diindikasikan keadaan jemaat Efesus pada saat

18 Joseph Christ Santo, "Strategi Menulis Jurnal Ilmiah Teologis Hasil Eksegesis," in Strategi Menulis Jurnal Untuk Ilmu Teologi (Semarang: Golden Gate Publishing, 2020), 121139. $1-3$.

${ }^{19}$ J.L. Ch. Abineno, Tafsiran Alkitab Surat Efesus (Jakarta: BPK Gunung Mulia, 1997),

${ }^{20}$ Joseph Christ Santo, "Makna Kesatuan Gereja dalam Efesus 4: 1-16," Jurnal Teologi El-Shadday 4, no. 2 (November 2017): 1-34. 
itu. Mereka adalah jemaat yang beriman dan bukti iman itu mereka tunjukkan dalam tindakan keseharian. Mereka berpegang pada iman dan membuat iman itu dikenal, dan mereka menunjukkan kasihnya dalam perbuatan untuk orang-orang kudus. ${ }^{21}$ Efesus 1:15-17 menyinggung motivasi Paulus menulis surat ini. Dengan sungguh-sungguh Paulus berdoa agar para pembaca suratnya bertumbuh dalam iman, kasih, kebijaksanaan, dan wahyu dari Bapa yang perkasa.

Di sisi lain penduduk Efesus yang belum mengenal Kristus sudah terbiasa dengan praktik-praktik okultisme seperti nekromansi, eksorsisme, dan segala bentuk seni sihir, ${ }^{22}$ serta kebobrokan moral mereka yang dapat diindikasikan dari adanya rumah lokalisasi prostitusi, meja perjudian, dan fitur seksual berlebihan dari patung-patung Diana, dewi kesuburan mereka. ${ }^{23}$ Tampak sekali kontras antara pertumbuhan iman orang-orang yang sudah di dalam Kristus dan mereka yang masih di luar Kristus. Paulus menegaskan dalam beberapa bagian dari suratnya bahwa jemaat Efesus tidak boleh memiliki kebiasaan yang sama dengan orang-orang di sekitar mereka yang belum mengenal Kristus dan masih hidup dalam gelap, sebaliknya jemaat harus menjadi anak-anak terang. Surat Efesus memiliki banyak persamaan dengan surat Kolose. Mungkin surat Efesus ditulis tidak lama sesudah surat Kolose, dan kedua surat dibawa ke tempat tujuan dalam satu kali perjalanan oleh seorang kawan sekerja Paulus yang bernama Tikhikus (Ef. 6:21; Kol. 4:7). ${ }^{24}$

\section{Spiritualitas}

Ada dua kalimat sejajar yang maknanya bertolak belakang dalam Efesus 5:18. Kedua kalimat tersebut memiliki modus imperatif; kalimat yang pertama adalah imperatif negatif (perintah untuk tidak dilakukan atau larangan), sedangkan kalimat kedua memiliki modus imperatif tanpa partikel negatif (perintah untuk dilakukan). Secara literal dalam bahasa Indonesia masingmasing adalah larangan untuk tidak mabuk anggur dan perintah untuk penuh dengan Roh. Jika kalimat pertama diubah ke dalam bentuk positif, sehingga keduanya berupa perintah untuk dilakukan, maka perintah itu adalah agar jemaat hidup dalam kesadaran dan hidup dikendalikan oleh Roh. Peneliti memandang

21 "Gill's Exposition of the Entire Bible Online," Biblos.Com, August 2011, Eph. 1:15.

${ }^{22}$ Charles Hodge, A Commentary on the Epistle to the Ephesians (Bellingham, WA: Logos Research Systems, Inc., 2009), v.

${ }^{23}$ Walter A. Elwell and Barry J. Beitzel, Baker Encyclopedia of the Bible, Map on Lining Papers (Grand Rapids, Michigan: Baker Book House, 1988), 710.

${ }^{24}$ Alkitab Penuntun Hidup Berkelimpahan (Malang: Gandum Mas, 2000), Efesus. 
bahwa dua perintah ini adalah indikator spiritualitas, yang pemaparan dari kedua indikator tersebut dijabarkan berikut ini.

Hidup dalam Kesadaran

Sebelum mengemukakan tentang $\pi \lambda \eta \rho \circ \tilde{\theta} \theta \varepsilon \dot{\varepsilon} v \pi v \varepsilon v ́ \mu \alpha \tau \imath$ (plērousthe en pneumati), Rasul Paulus menyampaikan imperatif negatif atau larangan $\mu \grave{\eta}$


frasa ini diterjemahkan LAI dengan, "janganlah kamu mabuk oleh anggur." Terjemahan-terjemahan lain dalam bahasa Indonesia, seperti Alkitab Terjemahan Lama, Alkitab Yang Terbuka, Bahasa Indonesia Masa Kini, dan Firman Allah Yang Hidup, tidak jauh berbeda dalam pemilihan kata. Jika dilihat dari kala yang digunakan oleh kata kerja $\mu \varepsilon \theta v ́ \sigma \kappa \varepsilon \sigma \theta \varepsilon$ (methuskesthe) adalah kini, yang berarti sedang terjadi atau terus-menerus. Dalam modus imperatif negatif, diartikan "berhentilah" atau "jangan terus-menerus", sehingga arti yang

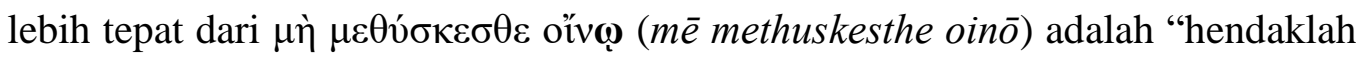
kamu berhenti mabuk anggur" atau "janganlah kamu terus-menerus mabuk anggur."

Perintah untuk tidak mabuk oleh anggur dapat ditafsirkan secara harfiah yaitu menjaga diri dari minuman keras yang dapat menyebabkan mabuk. Namun, imperatif negatif ini dapat diperluas maknanya. Mabuk adalah kondisi tidak sadar; orang yang mabuk tidak menyadari apa yang dilakukannya (Ams. 23:35). Larangan mabuk anggur dapat diartikan sebagai peringatan untuk mewaspadai hal-hal yang dapat membuat orang Kristen kehilangan kesadaran penuh. Salah satu yang dapat menyebabkan kehilangan kesadaran adalah larut dalam emosi; orang yang larut dalam emosi kadang-kadang melakukan tindakan-tindakan di luar kesadarannya. Ayat ini dapat ditafsirkan, bahwa orang Kristen harus berhenti dari segala hal yang dapat membuat lupa diri, dan selanjutnya berada dalam kewaspadaan penuh. Dalam 1 Tesalonika 5:6-8 Paulus mengaitkan kesadaran dan sikap berjaga-jaga dengan suasana siang hari, sebagai kontras dari tidur dan mabuk yang dikaitkan dengan suasana malam hari. Kesadaran penuh tersebut digambarkan seperti prajurit yang siap untuk berperang.

Di bagian lain Alkitab dicatat oleh Lukas dalam Kisah Para Rasul 2, bahwa ada kemiripan antara orang yang mabuk anggur dengan orang yang penuh Roh. Orang-orang di Yerusalem melihat mereka yang dipenuhi Roh

${ }^{25}$ Nestle - Alland, Novum Testamentum Graece, ed. Institute for Newtestament Textual Research, 28th ed. (Stuttgart: Deutshe Bibel Gesellschaft, 2012).

${ }^{26}$ Alkitab Terjemahan Baru (Jakarta: Lembaga Alkitab Indonesia, 2008), Ef. 5:18. 
Kudus sekilas seperti orang yang mabuk anggur (Kis. 2:13). Tetapi Petrus menegaskan bahwa mereka bukan mabuk anggur seperti yang dikira, tetapi mereka sedang dipenuhkan Roh Kudus sebagaimana pernah dijanjikan sebelumnya ketika Yesus masih bersama-sama dengan mereka (Kis. 2:15). Kemudian pada Efesus 5:18 kedua hal ini dibandingkan oleh Rasul Paulus sebagai kontradiksi. Dari uraian tentang larangan mabuk anggur di atas dapat disimpulkan, bahwa indikator yang pertama dari spiritualitas adalah berada dalam kesadaran penuh.

\section{Hidup Dikendalikan oleh Roh}


bahwa penuh dalam Roh adalah perintah. Alkitab Terjemahan Baru menuliskan, "hendaklah kamu penuh dengan Roh." ${ }^{27}$ Kata $\pi \lambda \eta \rho о \tilde{\theta} \theta \varepsilon$ (plèrousthe) adalah kata kerja imperatif dan pasif, dari kata $\pi \lambda \eta \rho o ́ \omega$ (pleroō) yang artinya penuh atau melimpah. Kata yang digunakan dalam kata kerja ini adalah kini, yang berarti tindakan yang sedang dilakukan atau terus-menerus dilakukan. ${ }^{28}$ Dengan demikian arti $\pi \lambda \eta \rho 0 \tilde{\theta} \theta \varepsilon$ (plērousthe) adalah: Hendaklah kalian terus-menerus dipenuhi atau dilimpahi. Frasa $\dot{\varepsilon} v \pi v \varepsilon v ́ \mu \alpha \tau$ (en pneumati) artinya di dalam Roh. Dengan demikian penerjemahan yang lebih tepat adalah "Hendaklah kamu terus-menerus dipenuhi di dalam Roh." Kata depan yang lebih tepat adalah "di dalam" bukan "dengan". Penerjemahan yang lebih tepat ini berimplikasi pada makna: keadaan penuh Roh bukan seperti bejana yang dituangi hingga penuh tetapi seperti bejana yang ditenggelamkan hingga penuh. Ilustrasi bejana yang ditenggelamkan di dalam cairan menggambarkan bahwa orang yang penuh Roh Kudus adalah orang yang seluruh hidupnya berada dalam penguasaan dan pengendalian Roh Kudus. Keadaan di bawah kendali Roh Kudus ini bukan terjadi pada suatu titik peristiwa saja, melainkan harus terus-menerus terjadi.

Secara khusus perintah penuh Roh Kudus mengingatkan jemaat Efesus pada peristiwa pada saat mula pertama jemaat ini didirikan. Pada saat itu dua belas orang di Efesus mengalami dipenuhkan Roh Kudus dan berkata-kata dalam basaha roh setelah mendapat penumpangan tangan dari Rasul Paulus (Kis 19:1-7). Perintah ini sekaligus mengingatkan bahwa perjalanan rohani jemaat Efesus tidak lepas dari kendali Roh Kudus, dan jemaat Efesus harus memertahankan kondisi tersebut. Jemaat Efesus yang sudah memulai perjalanan

${ }^{27}$ Alkitab Terjemahan Baru.

${ }^{28}$ Hasan Sutanto, Perjanjian Baru Interlinier Yunani-Indonesia Dan Konkordansi Perjanjian Baru (PBIK) (Jakarta: Lembaga Alkitab Indonesia, 2019). 
rohaninya dengan dipimpin oleh Roh Kudus sepatutnya tetap dipimpin Roh Kudus sampai kepada seluruh kebenaran. Arifianto dan Sumiwi menegaskan, bahwa setiap orang percaya seharusnya dipimpin oleh Roh Kudus kepada seluruh kebenaran. ${ }^{29}$

Jika penglihatan yang dilihat oleh Yehezkiel mengenai sungai yang mengalir keluar dari bait suci (Yeh. 47) dikaitkan dengan pernyataan Yesus tentang karya Roh Kudus yang berkarya dalam hidup seseorang (Yoh. 7:38-39); maka dapat dijelaskan sebagai berikut. Karya Roh Kudus dalam diri manusia tidak hanya sampai pada mendiami hari manusia, ${ }^{30}$ tetapi orang yang mau dipimpin Roh Kudus akan semakin mengalami penguasaan Roh Kudus atas hidupnya. Akhir perjalanan nabi Yehezkiel menyusuri aliran sungai adalah ketika ketinggian permukaan air sudah melampaui tinggi badannya, sehingga ia harus berenang di dalam aliran sungai. Demikian pula orang yang berjalan dalam pimpinan Roh Kudus akan sampai pada keadaan di mana ia sepenuhnya dikuasai oleh Roh Kudus. ${ }^{31}$

Dari uraian tersebut di atas disimpulkan bahwa indikator kedua dari spiritualitas adalah seseorang yang ada dalam kendali Roh Kudus. Maka dari kedua indikator spiritualitas di atas dapat dibangun definisi spiritualitas secara biblikal: Spiritualitas orang Kristen adalah kondisi seorang Kristen yang mampu menguasai diri karena rohnya ada dalam kendali Roh Kudus.

\section{Spiritualitas dalam Peribadahan}

Frasa $\pi \lambda \eta \rho о \tilde{\theta} \theta \varepsilon \dot{\varepsilon} v \pi v \varepsilon u ́ \mu \alpha \tau \imath$ (plērousthe en pneumati) yang dituliskan dalam ayat 18 tidak berdiri sendiri secara gramatikal. Frasa dengan kata kerja modus imperatif ini diikuti dengan beberapa kata kerja modus partisipel. Kata kerja modus partisipel tidak dapat berdiri sendiri, tetapi bergantung kepada kata kerja lain yang menjadi kata kerja utama dalam kalimat. Adanya lima kata kerja partisipel yang menyertai frasa $\pi \lambda \eta \rho 0 \tilde{\theta} \theta \varepsilon \dot{\varepsilon} v \pi v \varepsilon v ́ \mu \alpha \tau \imath$ (plèrousthe en pneumati) menunjukkan bahwa kelima kata kerja ini merupakan penjelasan atau tindakan yang terkait dengan kata kerja $\pi \lambda \eta \rho \circ \tilde{\theta} \theta \varepsilon$ (plērousthe), yaitu $\lambda \alpha \lambda \circ \tilde{v} v \varepsilon \varepsilon \varsigma$

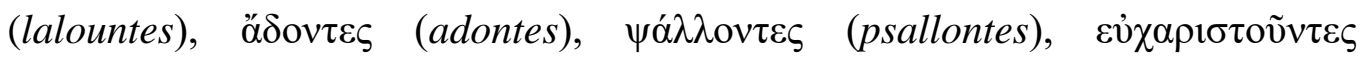

${ }^{29}$ Yonatan Alex Arifianto and Asih Rachmani Endang Sumiwi, "Peran Roh Kudus Dalam Menuntun Orang Percaya Kepada Seluruh Kebenaran Berdasarkan Yohanes 16: 13," DIEGESIS: Jurnal Teologi Kharismatika 3, no. 1 (2020): 1-12.

${ }^{30}$ Joseph Christ Santo, "Roh Kudus Yang Mendiami Menurut Yohanes 14:17," Jurnal Teologi El-Shadday 2, no. 1 (2014): 61-74.

${ }^{31}$ Asih Rachmani Endang Sumiwi, “Analisis Biblika Baptisan Roh Kudus Dan Penuh Dengan Roh Kudus," FIDEI: Jurnal Teologi Sistematika dan Praktika 1, no. 1 (2018): 1-20. 


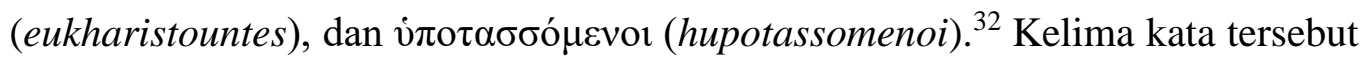
berhubungan dengan ibadah sebagaimana akan dijelaskan pada pembahasan selanjutnya, dan kelima kata yang tidak dapat berdiri sendiri tersebut harus bergantung kepada kata kerja utama, yaitu $\pi \lambda \eta \rho \circ \tilde{\theta} \theta \varepsilon \dot{\varepsilon} v \pi v \varepsilon v ́ \mu \alpha \tau \imath$ (plërousthe en pneumati). Artinya, ibadah yang benar adalah ibadah yang didasari spiritualitas yang benar, yaitu penuh dengan Roh.

Sebelum Rasul Paulus berbicara kepada jemaat Efesus tentang spiritualitas dalam peribadahan, Yesus sudah lebih dulu berbicara tentang spiritualitas dalam ibadah ketika berbicara dengan perempuan Samaria. Ibadah yang benar tidak lagi dibatasi dengan tempat ibadah atau situs, sebab dikatakan bahwa penyembah yang benar tidak terikat dengan bait suci di gunung Gerizim atau bait suci Yerusalem, melainkan akan menyembah Bapa dalam roh dan kebenaran (Yoh. 4:23-24). Ada kesamaan antara frasa dalam Efesus 5:18 dan Yohanes 4:23-24, yaitu $\dot{\varepsilon} v \pi v \varepsilon v ́ \mu \alpha \tau \imath$ (en pneumati) yang artinya di dalam roh (atau Roh); yang pertama menyebutkan dipenuhkan di dalam roh dan yang kedua menyebutkan menyembah (yang sama artinya dengan beribadah) di dalam roh. Dengan demikian ibadah yang benar bukanlah dilihat dari segi lahiriah orang yang beribadah; ibadah yang benar adalah ibadah yang dilakukan orang yang memiliki spiritualitas yang benar.

\section{Aspek Pertama: Saling Memerkatakan Mazmur, Kidung Pujian, Nyanyian Rohani}

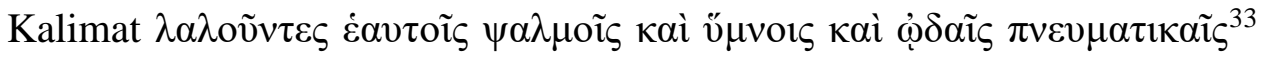
(lalountes heautois psalmois kai humnois kai ōdais pneumatikais) dalam Alkitab Terjemahan baru diterjemahkan sebagai "berkata-katalah seorang kepada yang lain dalam mazmur, kidung puji-pujian dan nyanyian rohani." ${ }^{34}$ Kalimat ini mengandung kata ganti refleksif yang diterjemahkan seorang kepada yang lain. Unsur refleksif ini menunjukkan bahwa keberadaan seseorang dikuasai Roh tidak hanya berdampak pada diri orang itu sendiri tetapi juga bagi orang-orang lain dalam persekutuan. Masing-masing anggota tubuh Kristus oleh pimpinan Roh memerkatakan mazmur, kidung pujian, dan nyanyian rohani bagi sesama.

Mazmur, kidung pujian, dan nyanyian rohani merupakan ciri khas dalam peribadahan Kristen. Salah satu segmen dalam liturgi ibadah Kristen adalah adanya mazmur, kidung pujian, dan nyanyian rohani. Ada yang menarik dari

\footnotetext{
${ }^{32}$ BibleWorks 7.0.012g (2006).

${ }^{33}$ Alland, Novum Testamentum Graece.

${ }^{34}$ Alkitab Terjemahan Baru.
} 
struktur pembahasan yang dilakukan oleh Paulus, bahwa perintah untuk penuh dengan Roh diikuti dengan kata kerja partisipel memerkatakan mazmur, kidung pujian, dan nyanyian rohani. Ini berarti memerkatakan mazmur, kidung pujian, dan nyanyian rohani adalah ekspresi dari orang yang penuh Roh. Hal ini tidak dapat dibalik, yaitu memerkatakan mazmur, kidung pujian, dan nyanyian rohani dengan maksud supaya penuh dengan Roh. Orang Kristen yang memiliki spiritualitas yang baik, yaitu yang penuh dengan Roh, salah satu indikasinya adalah memerkatakan bagi sesamanya mazmur, kidung pujian, dan nyanyian rohani.

Jika menyimak lirik lagu-lagu yang dinyanyikan dalam ibadah, ada lirik lagu yang merupakan hubungan vertikal manusia dengan Allah, berupa pengagungan kepada Allah, keyakinan kepada Allah, atau doa. Ada pula lirik lagu yang merupakan hubungan horizontal manusia dengan sesamanya, berupa kesaksian tentang hidup Kristen, ajakan untuk beribadah, atau penguatan bagi sesama yang sedang dalam pergumulan hidup. Kedua tipe lirik lagu ini ada di berbagai denominasi gereja, baik gereja-gereja arus utama maupun PentakostaKarismatik. Tetapi peneliti mengamati, bahwa pada dekade terakhir ada kecenderungan ibadah di sebagian gereja Pentakosta-Karismatik kurang memerhatikan aspek horizontal. Dengan alasan bahwa titik tekan ibadah adalah hubungan vertikal manusia dengan Allah, relasi dengan sesama saat ibadah mulai berkurang. Peneliti mengamati hal ini dari kalimat lagu-lagu yang dinyanyikan di gereja cenderung pada pola vertikal, yaitu hubungan jemaat dengan Allah. Beberapa lagu yang bertema membangun persekutuan dengan sesama warga jemaat mulai ditinggalkan. Ekses negatif dari penggunaan lagulagu yang tidak lagi menyentuh aspek horizontal adalah warga jemaat tidak berinteraksi dengan sesama warga jemaat yang hadir dalam ibadah, dan bisa menjadi terasing di tengah-tengah kehadiran orang banyak. Bahkan di beberapa gedung ibadah yang besar (megachurch) interaksi warga jemaat dengan sesamanya saat beribadah pun semakin berkurang. Padahal jika memerhatikan ayat ini, aspek horizontal dari lagu-lagu yang dinyanyikan dalam peribadahan tidak boleh terabaikan. Penggunaan kata "saling" atau "seorang kepada yang lain" merupakan aspek horizontal yang harus diperhatikan dalam penggunaan lagu-lagu di gereja.

\section{Aspek Kedua: Bernyanyi dan Bermazmur bagi Tuhan}


dalam pembahasan ini. Kedua kata kerja tersebut memiliki kemiripan makna, 


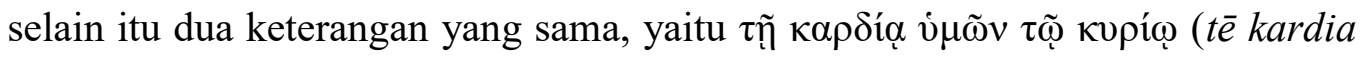
humōn tō kuriō), sama-sama menjelaskan kedua kata kerja partisipel tersebut.


psallontes tē kardia humōn tō kuriō) diterjemahkan dalam Alkitab Terjemahan Baru sebagai "Bernyanyi dan bersoraklah bagi Tuhan dengan segenap hati." 36 Dalam hal ini peneliti lebih memilih menerjemahkan dengan "Bernyanyi dan bermazmur bagi Tuhan dengan segenap hati."

Bernyanyi dan bermazmur bagi Tuhan memiliki kaitan dengan aspek yang pertama, yaitu saling memerkatakan mazmur, kidung pujian, dan nyanyian rohani. Kedua aspek ini telah menjadi bagian formal yang dilakukan dalam ibadah-ibadah di gereja. Jika aspek yang pertama dengan jelas menunjukkan hubungan horizontal sesama warja jemaat yang hadir dalam peribadahan, aspek kedua ini dengan jelas menunjukkan hubungan vertikal antara umat dengan Allah. Aspek pertama dan kedua saling berhubungan dan saling melengkapi. Jika lagu-lagu yang dinyanyikan dalam ibadah hanya menyentuh sisi horizontal, maka pertemuan tersebut tidak bisa disebut sebagai ibadah karena tidak ada bedanya dengan pertemuan masyarakat; sebaliknya jika hanya menyentuh sisi vertikal, maka pertemuan ibadah tidak ada ubahnya dengan ibadah pribadi karena tanpa disadari masing-masing akan abai terhadap orang lain yang ada di sekitarnya.

\section{Aspek Ketiga: Mengucap Syukur Senantiasa}

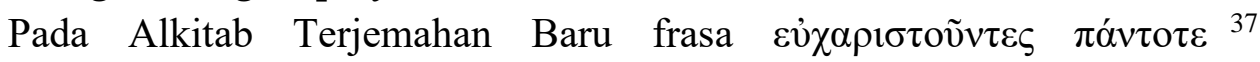
(eukharistountes pantote) diterjemahkan, "Ucaplah syukur senantiasa." 38

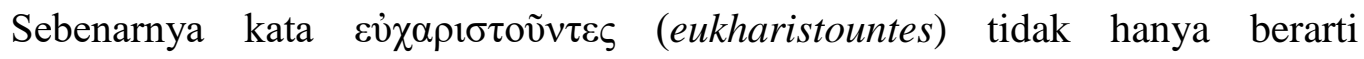
mengucap syukur, tetapi juga berterima kasih. Karena keterbatasan penerjemahan, maka padanan yang digunakan adalah mengucap syukur, sehingga seolah-olah tindakan ini hanya dalam konotasi vertikal kepada Allah. Sesuai konteks kalimat, Alkitab Terjemahan Baru menggunakan padanan kata

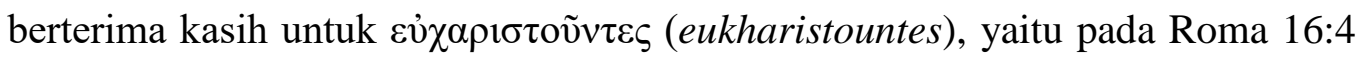
ketika Rasul Paulus berterima kasih kepada jemaat Roma. Ini menunjukkan

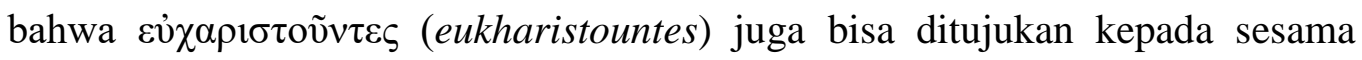
manusia.

\footnotetext{
${ }^{35}$ Alland, Novum Testamentum Graece.

${ }^{36}$ Alkitab Terjemahan Baru.

${ }^{37}$ Alland, Novum Testamentum Graece.

${ }^{38}$ Alkitab Terjemahan Baru.
} 


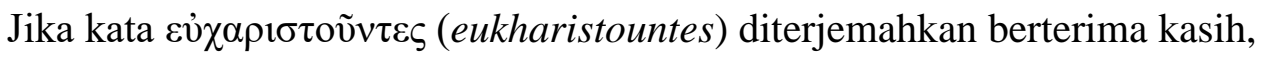
maka implikasinya adalah memberikan respons positif atas apa pun yang telah dilakukan orang lain. Orang Kristen dengan spiritualitas yang baik akan mudah mengucapkan terima kasih kepada sesamanya. Entah pertolongan diberikan dengan motivasi tulus atau pamrih terselubung, setiap orang sepatutnya memberikan ucapan terima kasih atas pertolongan yang diterimanya. Kelalaian mengucapkan terima kasih kadang-kadang menimbulkan rasa tidak nyaman pada pihak yang sudah memberikan pertolongan. Ucapan terima kasih adalah kata-kata sederhana tetapi mampu menciptakan keharmonisan dalam ruang sosial.

\section{Aspek Keempat: Saling Merendahkan Diri}

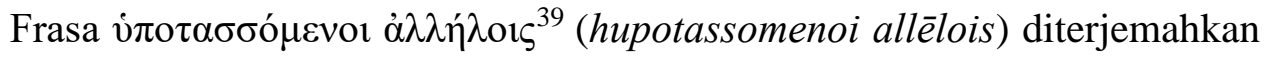
"rendahkanlah dirimu seorang kepada yang lain" pada Alkitab Terjemahan Baru. ${ }^{40}$ Ibadah dengan spiritualitas yang benar ditandai dengan sikap merendahkan diri. Teladan hidup orang Kristen adalah Kristus; dan Rasul Paulus telah memberikan pemaparan sedemikian gamblang, khususnya kepada jemaat Filipi, agar memiliki pikiran dan perasaan Kristus, bahwa Kristus yang adalah Allah tidak memertahankan keberadaan-Nya, sebaliknya merendahkan diri sedemikian rupa bahkan sampai mati di kayu salib (Flp. 2:5-11).

Alkitab mencatat contoh ibadah tanpa spiritualitas yang benar yang justru menghasilkan kesombongan. Lukas 18:11-12 mengisahkan orang Farisi yang beribadah dalam kesombongan, dengan perasaan lebih suci dan lebih saleh dari pemungut cukai yang beribadah bersama pada saat itu. Di hadapan Allah, orang Farisi itu menceritakan tindakan saleh yang telah dilakukannya, dan lebih membicarakan hal itu daripada kebutuhannya akan Allah. Tujuannya pergi ke Bait Allah seolah-olah untuk memberi tahu Allah betapa salehnya dia. Ia juga menganggap rendah semua orang lain, ia merasa diri lebih baik dari siapa pun. Ini adalah sikap meninggikan diri dan memosisikan diri sebagai hakim bagi sesamanya. Yesus menilai orang Farisi tersebut tidak mendapatkan manfaat dari ibadahnya dan pulang ke rumahnya bukan sebagai orang yang dibenarkan Allah.

Di bagian lain dalam Alkitab juga disebutkan adanya ibadah yang disertai dengan kesombongan. Di Kolose ada orang-orang yang tampaknya merendahkan diri dalam ibadah tetapi sebenarnya merasa diri lebih hebat dari

\footnotetext{
${ }^{39}$ Alland, Novum Testamentum Graece.

${ }^{40}$ Alkitab Terjemahan Baru.
} 
sesamanya, karena menganggap dirinya telah mendapatkan pengalaman supranatural lewat ibadahnya tersebut (Kol. 2:18). Paulus memeringatkan jemaat di Kolose agar mereka tidak terjebak dalam kesombongan ibadah seperti itu.

Kemegahan diri dan kesombongan adalah sikap yang berlawanan dengan kerendahan hati. Kemegahan diri dan kesombongan bukan ciri kasih (1Kor. 13:4), dan ikatan persatuan tidak dapat dibangun tanpa kasih (Kol. 3:14). Orang dengan spiritualitas yang baik akan merendahkan diri terhadap sesamanya. Kerendahan hati adalah awal dari keharmonisan.

\section{Spiritualitas dalam Peribadahan dan Keharmonisan Umat}

Alkitab mencatat bahwa bahasa roh terucap dari orang yang penuh dengan Roh, tetapi spiritualitas tidak semata-mata diukur dari bahasa roh seseorang. Bahkan Paulus memeringatkan jemaat Korintus, bahwa ibadah bisa menjadi kacau jika setiap orang yang hadir dalam ibadah berlomba-lomba menunjukkan karunia bahasa roh yang dimilikinya. ${ }^{41}$ Secara tersirat bahasa roh tidak selalu menunjukkan spiritualitas seseorang. Justru surat Efesus menunjukkan bahwa spiritualitas diindikasikan dalam sikap dan tindakan yang benar dalam ibadah. Irawan mengemukakan, bahwa ibadah yang benar yang benar terjadi pada saat Roh Kudus menggerakkan atau memberdayakan manusia untuk menyembah Allah. ${ }^{42}$ Rajagukguk mengemukakan hasil penelitiannya bahwa terdapat korelasi tidak langsung antara unsur-unsur ibadah Pentakosta dengan kedewasaan rohani orang Kristen. Ditunjukkan bahwa melakukan liturgi Pentakosta memberikan dampak bagi kedewasaan rohani. ${ }^{43}$

Ibadah seharusnya didasarkan pada spiritualitas. Ibadah tanpa spiritualitas adalah ibadah lahiriah dan tidak sampai kepada hakikat ibadah itu sendiri. Kepada Timotius, Rasul Paulus memeringatkan agar menjauhi orang-orang yang beribadah secara lahiriah tetapi pada hakikatnya memungkiri kekuatan ibadah itu (2Tim. 3:5). Pada masa Perjanjian Lama juga ada ibadah Israel yang dicela

${ }^{41}$ Desti Samarenna, “Analisis 1 Korintus 14:2-6 Tentang Karunia Berbahasa Roh Dan Bernubuat," Dunamis: Jurnal Penelitian Teologi dan Pendidikan Kristiani 2, no. 1 (2017): 111.

42 Toni Irawan, “'Menyembah Allah Dalam Roh Dan Kebenaran’ (Yohanes 4:20-26): Sebagai Suatu Landasan Praktek Ibadah Kristen Yang Alkitabiah,” Jurnal Teologi Amreta 3, no. 1 (2019): 55-81.

${ }^{43}$ Johanes S. P. Rajagukguk and Lion Sugiono, "Tinjauan Liturgis Unsur-Unsur Ibadah Pentakosta Terhadap Kedewasaan Rohani," MATHEO: Jurnal Teologi/Kependetaan 10, no. 1 (2020): 37-51. 
Tuhan karena mereka hanya beribadah dengan bibir (secara lahiriah) tetapi hati mereka jauh dari Tuhan (Yes.29:13). Hal ini menunjukkan bahwa bisa saja orang terlihat beribadah tetapi tanpa spiritualitas yang benar. Ibadah benar adalah ibadah yang didasari pada spiritualitas yang benar.

Peribadahan yang dituliskan dalam Efesus 5:19-21 adalah ibadah yang didasari pada spiritualitas yang dituliskan dalam Efesus 5:18. Ibadah ini mencakup kegiatan vertikal (tertuju kepada Allah) dan horizontal (tertuju kepada sesama). Namun demikian tidak sepenuhnya bisa dilakukan pemisahan apakah suatu tindakan diidentifikasi sebagai vertikal atau horizontal. ${ }^{44}$ Faktanya, aspek pertama dari spiritualitas dalam peribadahan mencakup tindakan vertikal dan horizontal sekaligus. Memerkatakan mazmur, kidung pujian, dan nyanyian rohani adalah bentuk kegiatan vertikal, tetapi kalimat ini juga disertai kata

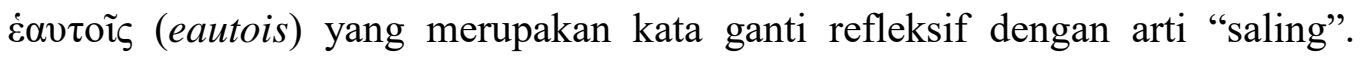
Artinya, memerkatakan mazmur, kidung pujian, dan nyanyian rohani tidak semata-mata tertuju kepada Allah tetapi juga melibatkan keberadaan sesama.

Konsep peribadahan yang benar tidak hanya menyentuh hal-hal vertikal, tetapi juga yang horizontal. Bila hal ini dilakukan dengan sungguh-sungguh, maka orang Kristen akan terhindar dari mabuk agama. Orang-orang yang mabuk agama cenderung memandang ibadah hanya pada aspek vertikal, sehingga kadang-kadang abai pada keberadaan orang lain di sekitarnya. Sebaliknya ibadah yang didasarkan pada spiritualitas yang benar akan memerhatikan sesama dan kemudian akan menghasilkan keharmonisan. Dengan kata lain, peribadahan yang didasarkan pada spiritualitas yang benar akan menghasilkan keharmonisan umat.

\section{Simpulan}

Hasil eksegesis dari Efesus 5:18-21 menunjukkan bahwa spiritualitas orang Kristen adalah kondisi seorang Kristen yang mampu menguasai diri karena rohnya ada dalam kendali Roh Kudus. Spiritualitas diekspresikan dalam empat aspek peribadahan: pertama, saling memerkatakan mazmur, kidung pujian, nyanyian rohani; kedua, bernyanyi dan bermazmur bagi Tuhan; ketiga, mengucap syukur senantiasa; keempat, saling merendahkan diri. Peribadahan orang Kristen tidak hanya menyentuh sisi vertikal yaitu hubungan manusia dengan Allah, tetapi juga sisi horizontal, yaitu hubungan manusia dengan

44 Firman Panjaitan and Marthin Steven Lumingkewas, "Ibadah Jemaat Kristen Kontemporer Abad 21 Dan Tinjauan Kritis-Liturgis," FIDEI: Jurnal Teologi Sistematika dan Praktika 2, no. 1 (2019): 159-182. 
sesamanya. Peribadahan yang didasarkan pada spiritualitas yang benar akan menghasilkan keharmonisan umat.

\section{Rekomendasi Penelitian Lanjutan}

Penelitian ini sampai pada kesimpulan bahwa spiritualitas orang Kristen terekspresi dalam peribadahan. Hasil penelitian ini dapat ditindaklanjuti dengan meneliti implementasi spiritualitas orang Kristen pada kelompok masyarakat tertentu melalui pendekatan kuantitatif.

\section{Daftar Pustaka}

Abineno, J.L. Ch. Tafsiran Alkitab Surat Efesus. Jakarta: BPK Gunung Mulia, 1997.

Alland, Nestle -. Novum Testamentum Graece. Edited by Institute for Newtestament Textual Research. 28th ed. Stuttgart: Deutshe Bibel Gesellschaft, 2012.

Arifianto, Yonatan Alex. "Kajian Biblikal Tentang Manusia Rohani Dan Manusia Duniawi." Jurnal Teruna Bhakti 3, no. 1 (2020): 12-24.

Arifianto, Yonatan Alex, and Asih Rachmani Endang Sumiwi. "Peran Roh Kudus Dalam Menuntun Orang Percaya Kepada Seluruh Kebenaran Berdasarkan Yohanes 16: 13." DIEGESIS: Jurnal Teologi Kharismatika 3, no. 1 (2020): 1-12.

Astuti, Tri. "Studi Biblika Spiritualitas Manusia Baru Berdasarkan Surat Efesus 4: 23-32.” SHIFT KEY: Jurnal Teologi dan Pengembangan Pelayanan 10, no. 1 (2020): 26-44.

Barus, Armand. "Spiritualitas Surat Kolose.” Jurnal Amanat Agung 12, no. 1 (2016): 39-62.

Baskoro, Haryadi, and Hendro H. Siburian. "Keseimbangan Antara Spiritualitas Dan Intelektualitas Dalam Pelayanan Pastoral-Karismatik." FIDEI: Jurnal Teologi Sistematika dan Praktika 2, no. 1 (2019): 123-144.

Baskoro, Paulus Kunto, and Indra Anggiriati. "Implementasi Pemuridan Dalam Efesus 4:11-16 Bagi Pertumbuhan Rohani Jemaat Di Masa Kini.” Sabda: Jurnal Teologi Kristen 2, no. 1 (2021): 242-265.

Elwell, Walter A., and Barry J. Beitzel. Baker Encyclopedia of the Bible, Map on Lining Papers. Grand Rapids, Michigan: Baker Book House, 1988.

Heuken, Adolf. Spiritualitas Kristiani: Pemekaran Hidup Rohani Selama Dua Puluh Abad. Jakarta: Yayasan Cipta Loka Caraka, 2002.

Hodge, Charles. A Commentary on the Epistle to the Ephesians. Bellingham, 
296 Fidei: Jurnal Teologi Sistematika dan Praktika, Vol. 4, No. 2, Des. 2021

WA: Logos Research Systems, Inc., 2009.

Hutagalung, Stimson. "Tugas Panggilan Gereja Koinonia: Kepedulian Allah

Dan Tanggung Jawab Gereja Terhadap Kemiskinan." Jurnal Koinonia 8, no. 2 (2016): 93-102.

Irawan, Toni. “'Menyembah Allah Dalam Roh Dan Kebenaran' (Yohanes 4:20-

26): Sebagai Suatu Landasan Praktek Ibadah Kristen Yang Alkitabiah.”

Jurnal Teologi Amreta 3, no. 1 (2019): 55-81.

Mutak, Alfius Areng. "Formasi Spiritualitas Sarana Menuju Kedewasaan

Spiritual." SOLA GRATIA: Jurnal Teologi Biblika dan Praktika 6, no. 1

(February 2020).

Nazara, Aroma. "Makna Doa Dalam Pembentukan Spiritualitas (Tinjauan

Teologis Terhadap Ajaran Paulus Mengenai Doa Dalam Surat Efesus)."

Sekolah Tinggi Teologi Amanat Agung, 2011.

Panjaitan, Firman, and Marthin Steven Lumingkewas. "Ibadah Jemaat Kristen

Kontemporer Abad 21 Dan Tinjauan Kritis-Liturgis." FIDEI: Jurnal

Teologi Sistematika dan Praktika 2, no. 1 (2019): 159-182.

Rajagukguk, Johanes S. P., and Lion Sugiono. "Tinjauan Liturgis Unsur-Unsur

Ibadah Pentakosta Terhadap Kedewasaan Rohani." MATHEO: Jurnal

Teologi/Kependetaan 10, no. 1 (2020): 37-51.

Samarenna, Desti. “Analisis 1 Korintus 14:2-6 Tentang Karunia Berbahasa Roh

Dan Bernubuat." Dunamis: Jurnal Penelitian Teologi dan Pendidikan

Kristiani 2, no. 1 (2017): 1-11.

Santo, Joseph Christ. "Makna Kesatuan Gereja dalam Efesus 4: 1-16." Jurnal Teologi El-Shadday 4, no. 2 (November 2017): 1-34.

—. "Roh Kudus Yang Mendiami Menurut Yohanes 14:17." Jurnal Teologi El-Shadday 2, no. 1 (2014): 61-74.

_. "Strategi Menulis Jurnal Ilmiah Teologis Hasil Eksegesis." In Strategi Menulis Jurnal Untuk Ilmu Teologi, 121-139. Semarang: Golden Gate Publishing, 2020.

Siagian, Rutam. "Pembaharuan Rohani Menurut Efesus 4:23 Sebagai Dasar

Pertumbuhan Jemaat." Jurnal Scripta Teologi dan Pelayanan Kontekstual 4, no. 2 (2017): 98-112.

Siahaan, Harls Evan R. "Bahasa Roh Dan Spiritualitas Perikoresis Dalam

Peristiwa Pentakosta: Analisis Reinterpretatif Kisah Para Rasul 2:1-13.”

Logia: Jurnal Teologi Pentakosta 2, no. 2 (2021): 18-31.

Sitepu, Elisabeth, Selamat Karo-Karo, and Ucok Rotama Situmorang. "Hubungan Nilai Spiritualitas Menurut Efesus 6:1-4 Dengan Budi Pekerti 
Siswa Kelas VI SDN 065015 Kemenangan Tani Medan Tuntungan Tahun Ajaran 2020/2021." Jurnal Pendidikan Religius 3, no. 1 (2021).

Sumiwi, Asih Rachmani Endang. "Analisis Biblika Baptisan Roh Kudus Dan Penuh Dengan Roh Kudus." FIDEI: Jurnal Teologi Sistematika dan Praktika 1, no. 1 (2018): 1-20.

Sutanto, Hasan. Perjanjian Baru Interlinier Yunani-Indonesia Dan Konkordansi Perjanjian Baru (PBIK). Jakarta: Lembaga Alkitab Indonesia, 2019.

Waharman, Waharman. "Peran Orang Tua Dalam Pertumbuhan Spiritualitas Anak: Sebuah Studi Eksegetis Efesus 6:1-4." Manna Rafflesia 4, no. 2 (October 2018): 116-129.

Alkitab Penuntun Hidup Berkelimpahan. Malang: Gandum Mas, 2000.

Alkitab Terjemahan Baru. Jakarta: Lembaga Alkitab Indonesia, 2008.

BibleWorks 7.0.012g (2006).

"Gill's Exposition of the Entire Bible Online." Biblos.Com, August 2011.

Kamus Besar Bahasa Indonesia. 5th ed. Badan Pengembangan Bahasa dan Perbukuan, Kementerian Pendidikan dan Kebudayaan Republik Indonesia, 2021. 